\title{
Design students' perceptions of a wiki enhanced English learning at university
}

\author{
M.S. Liashenko ${ }^{11 *}$ \\ ${ }^{1}$ Kozma Minin Nizhny Novgorod State Pedagogical University, Nizhny Novgorod, Russia
}

\begin{abstract}
This small-scale research is aimed at exploring design students' perceptions of collaborative English learning via a wiki site when doing a course of English for specific purposes (ESP) at the university. The learning community based on a wiki platform was launched to improve English skills in collaborative activities with the teacher and the peers. Semi structured interviews were conducted with the design students on a voluntary basis after the course completion. The data was analyzed using a qualitative analysis, which is resulted in five main categories describing design students' perceptions of their experiences. The results enabled to present a model of wiki enhanced learning which is grounded in theory of teaching-learning cycle. It is expected to provide an insight into the strengths and limitations of collaborative learning via wiki technology and address the challenges and outcomes of deploying wiki sites into the educational context at university.
\end{abstract}

\section{A problem statement}

The idea of wiki deployment into teaching and learning is not a new one: there is much research how wiki can be used effectively to improve various language skills especially writing and project activity. The pandemic period with the new requirement to teaching and the focus entirely on online format made educators think about the way how to engage students into collaborative activities and what platforms to choose from the variety of information communication technologies on the educational market. This paper presents the experience of the researcher of the ways how to deploy wiki sites to involve design students in learning collaboratively during ESP (English for specific purposes) program. The efficacy of using wiki tools for learning languages as a second one (L2) is well documented in the literature [1]. Despite a shift of current research in language learning towards social media [2], wiki technologies are used predominantly for collaborative writing in language training [1]. On the other hand, wiki sites create learning communities where collaborative goal-oriented practices can take place [3]. There is a need to research how exactly a wiki platform impacts students' professional learning in a new digitized context.

The wiki site (https://sites.google.com/view/art-and-design-mininuniver/home ) was designed by the researcher to provide a learning platform for collaboration and

1*Corresponding author: ipcs-profped@yandex.ru 
communication during the course of ESP for 2 year design students of Faculty of Design, Fine arts and Media technologies at Minin university (Russia). Special attention in the course was paid to teaching professionally oriented vocabulary. Because of the pandemic all the classes were transferred to Moodle system where a distant course was designed. Besides, online teaching was delivered to students via Zoom. The system offers obvious advantages and benefits but both teachers and students are reluctant to use the system. The previous research, which was conducted in my professional context, has shown unwillingness of delivering additional training via LMS or Moodle and a limited usage of collaborative potential of these technologies in teaching [4-7]. The rationale for wiki deployment was the idea of creating a space for asynchronous collaboration with peers in project activity and class or group discussion to share opinions as if the students were in a real class where they can share their works and voice their views.

The site was created using a free Google site platform with different pages for different groups. The students were invited to take part in several collaborative activities such as: designing a glossary of basic design vocabulary studied in Moodle; sharing their own art works or the paintings that they like in an art gallery with short descriptions; creating their own book cover and many more. The site was used as a learning platform the design of which was underpinned by the ideas collaboration and dialogue in the learning process taking place in communities or groups with different modes of participation, changing role of students and teachers, mediating functions of the technology $[8,9]$. The pedagogical design of a wiki site was underpinned by key principles of networked collaborative elearning [9] (table 1). The strategy involved numerous mediation activities (text, concepts, communication) embedded into the primary context of the curriculum and online interaction mediated with a wiki site. Wiki enhanced learning lasted for four months till the exam period in June 2020 and some exam materials, the course progress and final grades for the final exam were shared with the students via wiki too. The wiki site development consisted of several stages at which ethical considerations were considered. The initiation stage of the project was associated with the risk of low participation of students. The issue could be addressed by providing more information about the aims, tasks, the value of collaborative learning and outcomes. The participation should be voluntary because the wiki site is designed as a scaffolding learning platform outside traditional face-to face classes. At the engagement and exchange phase, the code of ethical conduct or wiki etiquette was presented by the teacher to delineate the rules of "co-exiting" in the learning community [2]. Here the principle of anonymity and confidentiality in sharing presentations and essays for peer- review must be considered. Well-designed ethical guidelines for students' wiki presence will lead to the greater awareness of risks/ benefits that such digital engagement and interaction could bring [10]. At the research phase the consent form to take part was designed in a written form and sent to the participants after the course was completed and grades were known. This is an important step for avoiding any imbalance in power relationships and reducing the fear of bias (students can be afraid of providing honest answers being dependent on their grades for the course).

Table 1. The design of a wiki-based community.

\begin{tabular}{|l|l|l|}
\hline $\begin{array}{l}\text { Model of a wiki } \\
\text { community }\end{array}$ & Principles & Tasks and activities \\
\hline Learning process & $\begin{array}{l}\text { Students' problems are the source } \\
\text { for social collaborative dialogic } \\
\text { learning }\end{array}$ & $\begin{array}{l}\text { Mediating the text, concepts and } \\
\text { communication underpinned by } \\
\text { students' needs and exam essentials }\end{array}$ \\
\hline Role of student & $\begin{array}{l}\text { Active constructor and a co- } \\
\text { presenter. Viewed as diverse } \\
\text { individuals having weak and strong } \\
\text { ties }\end{array}$ & $\begin{array}{l}\text { Different patterns of interactions } \\
\text { online (S-S /T-S/S-resources) }\end{array}$ \\
\hline
\end{tabular}




\begin{tabular}{|l|l|l|}
\hline $\begin{array}{l}\text { Model of a wiki } \\
\text { community }\end{array}$ & Principles & Tasks and activities \\
\hline Role of teacher & $\begin{array}{l}\text { Facilitator critical observer and co- } \\
\text { expert }\end{array}$ & $\begin{array}{l}\text { Mainly in mediating } \\
\text { communication and choosing the } \\
\text { content embedded into the } \\
\text { curriculum }\end{array}$ \\
\hline Assessment & Collaborative self-peer-teacher & $\begin{array}{l}\text { Mediating the concept in peer } \\
\text { assessment practices (formative } \\
\text { type) }\end{array}$ \\
\hline Learning outcomes & $\begin{array}{l}\text { Creation and sharing expertise/ } \\
\text { mastery of skills }\end{array}$ & $\begin{array}{l}\text { The alignment between mediation } \\
\text { and online collaboration }\end{array}$ \\
\hline ICT used & Wiki site & $\begin{array}{l}\text { Affordances of wiki for interaction } \\
\text { and collaboration online }\end{array}$ \\
\hline
\end{tabular}

\subsection{The objective of the work}

Wiki-technologies have been actively used by teachers to achieve the aim of collaboration and active equal participation in English learning activities [1]. Wiki sites are proposed as an effective scaffolding platform to support teaching and learning [11]. Scaffolding is a form of learner support provided in a variety of ways, assigning several roles and responsibilities for students and other participants in the educational environment [12]. The technology provides participants with the opportunity to download and upload the information, to get an easy access to the materials, to do projects collaboratively [13].

Speaking generally, wiki creates "architecture of participation" in shared learning spaces [14] or some type of community of practice where the knowledge is developed collectively, and the practice can be improved due to collective sharing. Being underpinned by the idea of collaboration, wiki sites are an open multimodal space where mediation activities can be designed by the teacher and practiced by learners. In other words, wiki collaborative environment provides an opportunity for students to learn how to work with others and how to create a community $[2,13]$. Google sites, as a free open tool, are used for educational purposes, though there is little research reporting the deployment of this technology. Overall, it is focused on writing skills and teachers' experiences and methods. This fact implies addressing the issue of how exactly a wiki site can scaffold students' learning activities and tasks designed intentionally by the teacher to increase collaboration and more student engagement in online interaction. Following Lund et al. [1] it is necessary to explore the alignment of "task design with the development of technological features that boost agents' awareness of different levels of collectivity that are involved in joint knowledge construction" (p. 410). Learning is seen not only through the connections between the agents and tasks in a wiki-mediated learning environment at a collective level, but also at an individual level to see how these individual experiences vary in terms of what is learnt and how $[15,16]$.

The method chosen for data analysis was based on qualitative methodology. The data was gathered through oral interviews and video recording via Zoom after the final exam and the course completion. Semi structured interviews were conducted with the design students who voluntary agreed to take part in the research. The invitation was prior sent to the participants where the purpose of the research and the format of the interviews were described by the researcher. The research question was focused on the way how design students perceived their learning experiences of using a wiki platform to study English during the pandemic period. The questionnaire consisted of six parts covering the following aspects: general impression, working with the text, collaborative tasks, wiki for discussion and interaction, ethics of wiki enhanced learning, students' recommendations, and ideas. The average length of an interview was about 38 minutes. The interviews enabled the 
researcher to analyze deeply students' perceptions concerning not only the language aspect but also psycho-pedagogical factors that could impact students' academic performance and motivation. The interviews $(\mathrm{N}=5)$ were video recorded with the permission of the participants, transcribed and then analyzed manually to identify basic convergent themes. The qualitative data was analyzed using Creswell's approach to qualitative methods and Tesch's eight steps in the coding process [17]. Each student was given a code to avoid a biased attitude when analysing the data: for example, student 1 (S1). The analysis resulted in several themes which enabled to develop and propose a theoretical model of a wiki enhanced learning in the professional teaching and learning.

\section{Materials and the results of the research}

The convergent themes were identified: tasks, collaboration, communication, assessment and motivation. These categories are logically connected following the course design. It must be started with carefully created and goal-oriented tasks that would engage design students in collaboration with peers and teacher-students communication. The final stage is the necessity of the assessment with the impact on extrinsic motivation of students. The synergy of these e is reported to influence indirectly also intrinsic motivation of students by appealing to their affective domains of learning [7]. The tasks can be represented in a variety of forms and formats: from examples and model answers to group collaborative projects. The students report the importance of having all resources in one place and having an open access to others' works. Besides, the tasks must be presented in a clear and a structured manner with visual aids to remember new words or information more quickly.

"The access to other papers was useful to know more about the peer's interests and.. sometimes to borrow their language" (S3). "It is a plus that you always have an access to all the materials... an all links are in one place” (S1).

Collaborative projects arouse great interest among the design students for various reasons. The respondents reported the novelty of the idea (S2; S4), professional direction of learning materials (S1); the opportunity to present one's own works and to see the others' (S4; S5). Overall, the respondents described these tasks as "interesting" and useful "design experience" (S1;S5;S3) in terms of editing, formatting, working with color and different fonts. The most interesting collaborative projects were named Art gallery (https://sites.google.com/view/art-and-design-mininuniver/art-gallery?authuser $=0$ ) and $\mathrm{A}$ Book cover (https://sites.google.com/view/art-and-design-mininuniver/group-18-1/myfavorite-book-cover?authuser $=0$ ). These projects were perceived as engaging and motivating. Collaboration was based on communication with the teacher and the peers. This theme describes the nature of wiki enhanced communication as asynchronous with no or little online and sustained interaction. The respondents report scarce chances of online discussion or chatting. According to the findings, communication must be of academic style with the teacher being a moderator and a facilitator of group activities. An interesting finding can be the sense of belonging that was experienced by the students doing the tasks. The students characterize communication via wiki as "friendly" "peaceful" and "safe" due to the teacher's presence and the academic nature of the tasks given. All the problems or disagreement were solved using a social networking site Vkontakte in order not to distract others from the academic context.

"It was interesting to read the comments of students and to see that my comments are read too" (S3). ".. that was one common goal, common motivation that made us closer to each other" (S2). " ...that was not pure supervision but the form of a friendly conversation as if it were a consultation or advice" (S4).

Despite the feeling of parity and freedom of self-expression all the participants state the importance of assessment, though there is no full agreement about the necessity of 
deadlines. The assessment must be underpinned by clear criteria which are known to students A model answer or the teacher's recommendations can be extremely helpful in understanding the task properly. The students liked the idea of peer review as in Moodle or in an offline class this format is limited to some extent. Assessment is extrinsic motivation, whereas a transparency of grades makes this process very competitive and stimulating in terms of inner motives $[18,19]$.

"If there were no grades, we wouldn't do anything...we'd better relax doing nothing " (S1) When I saw 100 grade for the answer, I got the understanding of the way how to improve my paper and there was a stimulus to get the same result" (S3).

The final theme that emerged after the data analyses was motivational sphere. Overall, the students described their experience as positive and useful because wiki enhanced learning provided new learning opportunities in comparison with the traditional teaching and learning: more freedom of designing your own learning space by choosing images, fonts and colors; an open access to other's works; the idea of ownership and a learning community; a visually appealing site that can be co-created together with the peers and the teacher; parity and consultation with the teacher who is an active participant of the process; peer assessment and constant individual feedback on every project from the teacher; any time access to all the materials being stored in one place (videos, glossary, model answers, course statistics etc.); variety of ICT embedded into teaching via wiki (Google forms, YouTube, Quizlet, Vkontakte etc.).

The themes identified can be grounded in the theory of Teaching- Learning Cycle (TLC) involving 4 key stages: building the context-based tasks- modelling the situationguided practice and independent construction [20]. Assessment and feedback are integral parts of the guided practice. The interconnected links between the themes can be presented by a theoretical model of a wiki enhanced professional learning of students where the first stage is associated with the task design, the second requires modelling situations of collaboration and communication via wiki, the third is connected with assessment both the teacher's and the peers and the final stage is reflecting and analyzing the learning outcomes which are stimulated either by intrinsic or extrinsic motivation. The interconnectedness between the identified themes characterising students' experiences can be visually presented by a theoretical model of a wiki enhanced professional learning of students.

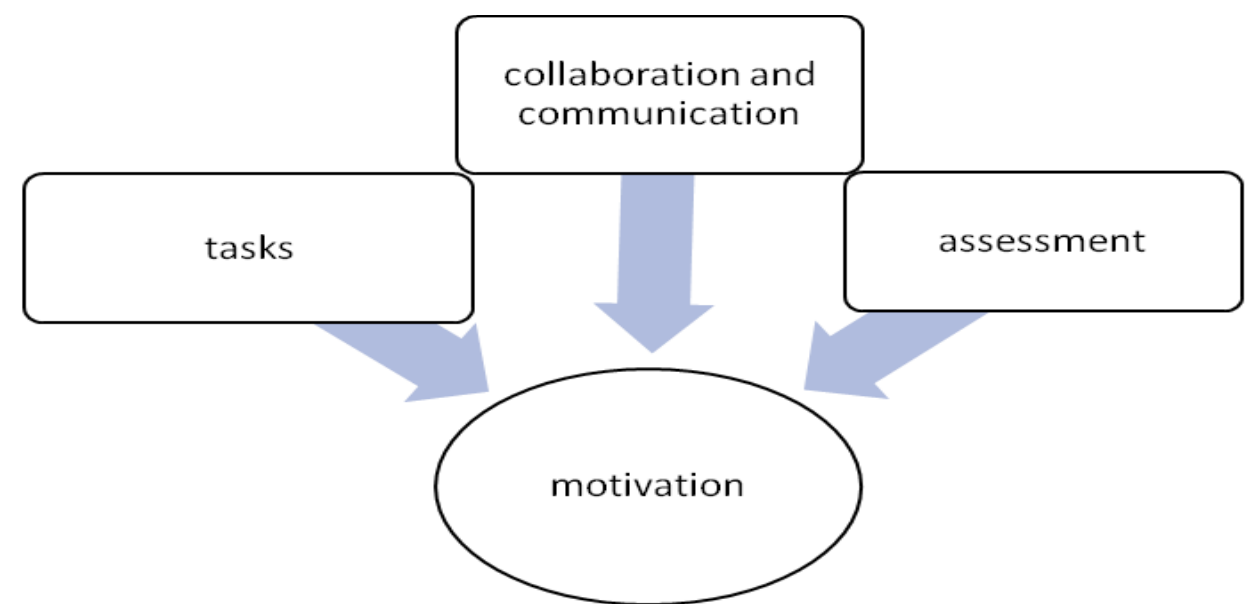

Fig 1. A theoretical model of a wiki enhanced professional learning of students.

The findings and the results from the data analysis are believed to contribute to different aspects of language learning. The possible pedagogical value of the research can be the following: 
i) provide more opportunities to improve skills in ESP course by scaffolding students in collaboration and interaction;

ii) engage learners in decision making and reflection about their learning through wiki and consequently increasing students' autonomy [13];

iii) empower students to strengthen their voices in a variety of collaborative forms that can be offered by wiki in combination with other digital forms of communication;

iv) create conditions for more inclusive educational environment given the variety of perspectives, patterns of participation, a safer environment which is built on trust, partnership, respect, equal distribution of power, freedom of speech, active learning and other ethical principles for supporting community [19].

The students are believed to benefit from the collaborative activities in a number of ways. Firstly, wiki enhanced learning can bring empowerment gains [20-22]. Being involved in a learning community based on parity and co construction of knowledge , students are likely to strengthen their voices in a variety of collaborative forms that can be offered by wiki technology in combination with other digital forms of communication. Secondly, there are some academic gains for students at an undergraduate level. They are likely to benefit from the exchange of knowledge with peers and a more experienced researcher/teacher [20]. New research/digital/communicative skills can be acquired or improved in collaborative activities [23]. Thirdly, this project can result in interpersonal communication gains. New forms of teacher-students' relationships in a collaborative learning environment are not linear and hierarchical as traditional classroom teaching [10]. Participatory approaches are expected to facilitate digital communication and make education process more inclusive due to a safer and friendlier environment [19, 21, 24].

\section{Conclusions}

The research addresses the necessity and describes an attempt to transfer collaborative tasks for English professional training of design students into non-traditional informal settings in the university educational environment [21]. The theoretical model and the gains outlined in the research can inform teachers' choices in designing and implementing wiki sites in teaching English for professional communication. The study is expected to contribute to the field of research by providing an alternative way of describing design students' experiences and presenting a holistic view on design students' perceptions of using a wiki based learning community in professional language training. This perspective moves away from just good or bad experiences of students [9]. The future research can be directed to analysing such interaction within the university educational environments using other methodological approaches.

\section{References}

1. M. Li, CALL-EJ, 13(1), 17-35 (2012)

2. J. Reinhardt, Social media in second and foreign language teaching and learning: Blogs, wikis, and social networking. (Language Teaching, 2019)

3. M. Henderson, N. Selwyn, R. Aston. Studies in HE, 42 (8), (2015)

4. M.S. Lyashenko, I.A. Malinina, I.A. Procedia-Social and Behavioral Sciences, 182, 8188 (2015).

5. O.A. Mineeva, M.P Prohorova, M.S. Liashenko. European Proceedings of Social and Behavioural Sciences (to be published) (2019) 
6. M.L. Gruzdeva, O.I. Vaganova, S.N. Kaznacheeva, N.V. Bystrova, A.V. Chanchina,. Lecture Notes in Networks and Systems 73, 1097-1103 (2020)

7. S.N. Sorokoumova, S.P. Elshansky, E.B. Puchkova, Yu.V. Suhovershina. Vestnik of Minin University. 8, (1), 10 (2020)

8. D. Passey, IEEE Transactions on Learning Technologies, 3(1), 68-81 (2010)

9. D. McConnell, Studies in continuing education, 24(1), 73-92(2002)

10. C. Fluehr-Lobban, Collaborative Anthropologies, 1, 175-182 (2008)

11. Y.C. Chao, H.C. Lo, Interactive Learning Environments, 19(4), 395-411 (2011)

12. C. McLoughlin, Distance Education, 23(2), 150-162, (2002)

13. G. Kessler, Language Learning \& Technology, 13(1), 79-95 (2009)

14. O’ Reilly, T. Open Sources, 2, 253-272. (2004)

15. J. Reinhardt, V. Zander, Calico Journal, 28(2), 326-344. (2011)

16. S. Booth, Procd. of the 6th Int. Conf on NL, 450-455 (2008)

17. J.W. Creswell, J.W. Sage Publications, 152 (2014)

18. N.I. Dunaeva, O.V. Suvorova, Vestnik of Minin University, 8, no. 1, 8 (2020)

19. D.A. Krathwohl, New York: David McKay Company. (1964)

20. B. Derewianka, P. Jones, P. South Melbourne, Vic: Oxford University Press. (2016)

21. K. Hacker, Sage publications. (2013)

22. A. Hart, D. Wolff, Planning, Practice \& Research, 21(1), 121-138 (2006)

23. M. Ripley, Oxon: Routledge, 154-172 (2008)

24. V. Hodgson, D. McConnell, L. Dirckinck-Holmfeld. Springer, New York, NY (2012) 